\title{
European agroforestry has no unequivocal effect on biodiversity: a time-cumulative meta-analysis
}

\author{
Anne-Christine Mupepele $e^{1,2^{*}} \mathbb{D}$, Matteo Keller ${ }^{2}$ and Carsten F. Dormann ${ }^{2}$
}

\begin{abstract}
Background: Agroforestry is a production system combining trees with crops or livestock. It has the potential to increase biodiversity in relation to single-use systems, such as pastures or cropland, by providing a higher habitat heterogeneity. In a literature review and subsequent meta-analysis, we investigated the relationship between biodiversity and agroforestry and critically appraised the underlying evidence of the results.

Results: Overall, there was no benefit of agroforestry to biodiversity. A time-cumulative meta-analysis demonstrated the robustness of this result between 1991 and 2019. In a more nuanced view silvopastoral systems were not more diverse in relation to forests, pastures or abandoned silvopastures. However, silvoarable systems increased biodiversity compared to cropland by $60 \%$. A subgroup analysis showed that bird and arthropod diversity increased in agroforestry systems, while bats, plants and fungi did not.
\end{abstract}

Conclusion: Agroforestry increases biodiversity only in silvoarable systems in relation to cropland. But even this result is of small magnitude, and single-study effect sizes were heterogeneous with sometimes opposing conclusions. The heterogeneity suggests the importance of other, usually unmeasured variables, such as landscape parameters or land-use history, influencing biodiversity in agroforestry systems.

Keywords: Species richness, Silvopasture, Silvopastoral, Silvoarable, Arthropods, Birds

\section{Background}

Agroforestry is a collective name for diverse land-use systems integrating tree husbandry with livestock or arable cultivation [1, 2]. It is a historical element of the European landscape with traditional agroforestry approaches such as large fruit orchards with extensive livestock grazing. Nowadays, new forms of agroforestry, e.g. short-rotation coppice in combination with crop rows, are implemented in some places [3]. Agroforestry is subdivided into silvopastoral systems, grazed by livestock or used for fodder production, and silvoarable systems, in which crops are

\footnotetext{
*Correspondence: anne-christine.mupepele@biom.uni-freiburg.de

${ }^{1}$ Nature Conservation and Landscape Ecology, University of Freiburg,

Tennenbacherstr. 4, 79106 Freiburg, Germany

Full list of author information is available at the end of the article
}

grown among trees [4]. Fields where trees are grown only at the edge, such as stream-side management zones or hedgerows adjacent to arable land, are also occasionally subsumed under agroforestry systems [4]. In these cases, the herbaceous and wooded components are usually not managed together and may have different owners. In our study, trees or shrubs adjacent to fields or pastures are not considered.

Biodiversity is threatened and particularly steep declines have been observed in intensively used agricultural areas [5-8]. Compared to monocultures, agroforestry systems increase heterogeneity in the landscape structure and potentially lead to increased biodiversity [5, 9-12]. Demonstrating a clear benefit for biodiversity could favour future subsidies for agroforestry systems by 


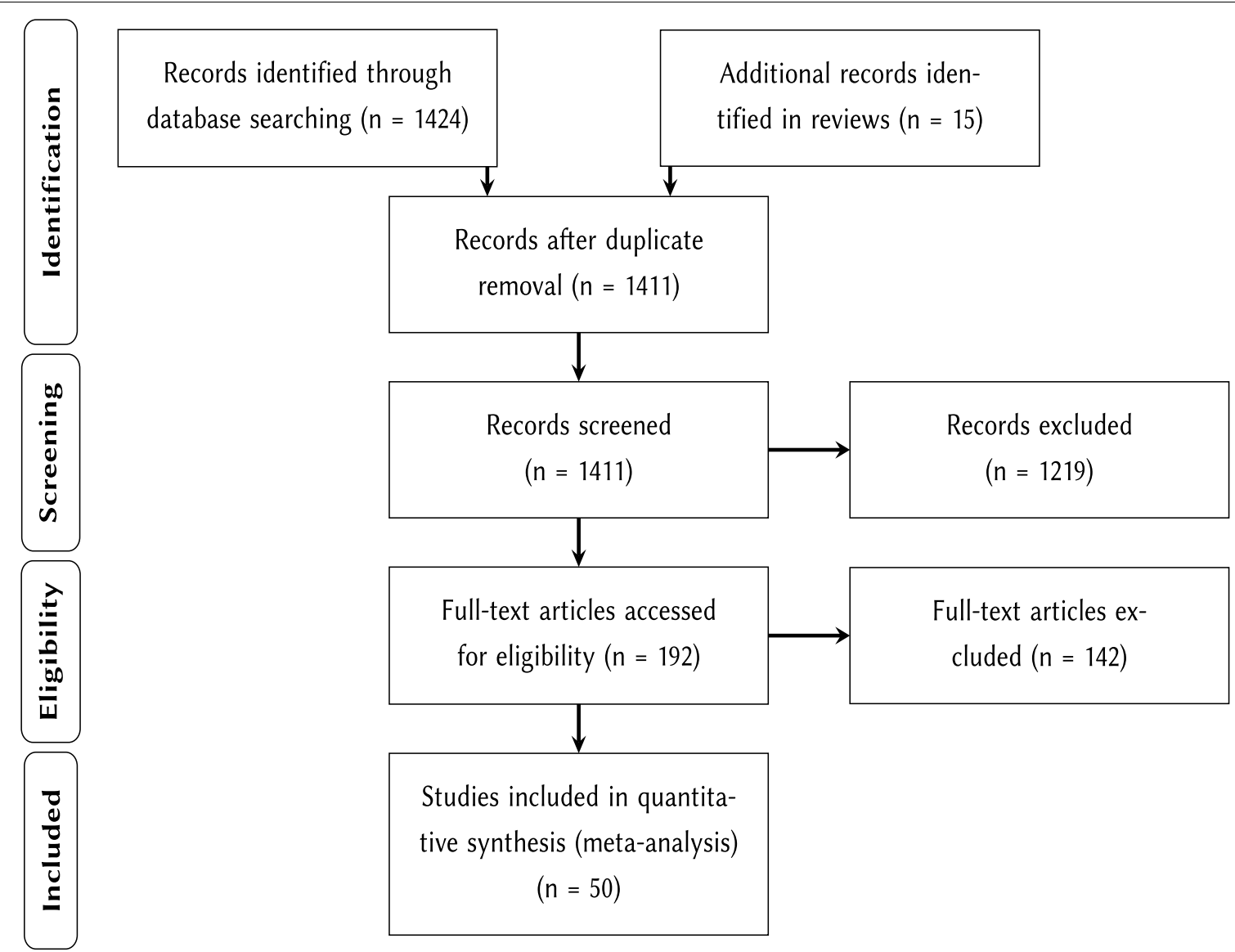

Fig. 1 PRISMA flow diagram $[24,25]$

the Common Agricultural Policy or its successor policies [13-17].

The benefits for biodiversity in agroforestry systems have been investigated particularly in the tropics, indicating that biodiversity can be improved by agroforestry in degraded and intensively cropped areas, while it remained lower in comparison to primary and secondary forests [18-20]. In the temperate zones, studies for species groups such as birds [21] and invertebrates [22] have shown equivocal effects on biodiversity. An earlier metaanalysis found a net increase of biodiversity across taxa and agroforestry systems in Europe; however it did not provide detailed information on the heterogeneity and robustness of their findings and was based on a broader definition of agroforestry including field-adjacent hedgerows and riparian buffers [23]. Here we provide an evidence update and a more explicit discussion of biodiversity in direct comparison to forests and agriculture and assess the robustness of the results by answering the following research questions:
(1) What is the effect of agroforestry on biodiversity relative to forests, pastures, cropland or abandoned, shrub-encroached agroforestry?

(2) Is the effect of agroforestry on biodiversity influenced by environmental variables, specifically the kind of agroforestry system (silvopasture or silvoarable), sampling method, the specific measure of biodiversity, sampling year, country, climate and the reference used?

(3) How strong and robust is the underlying evidence of these results?

\section{Results}

The literature search resulted in 1411 records from which 50 articles met all inclusion criteria (Fig. 1, Additional file 1, 2 and 7). Unique combinations of agroforestry systems (silvoarable or silvopastoral), control types (forest, cropland, pasture or abandoned agroforestry systems) and taxonomic groups per study led to 69 effect sizes used in the meta-analysis. 


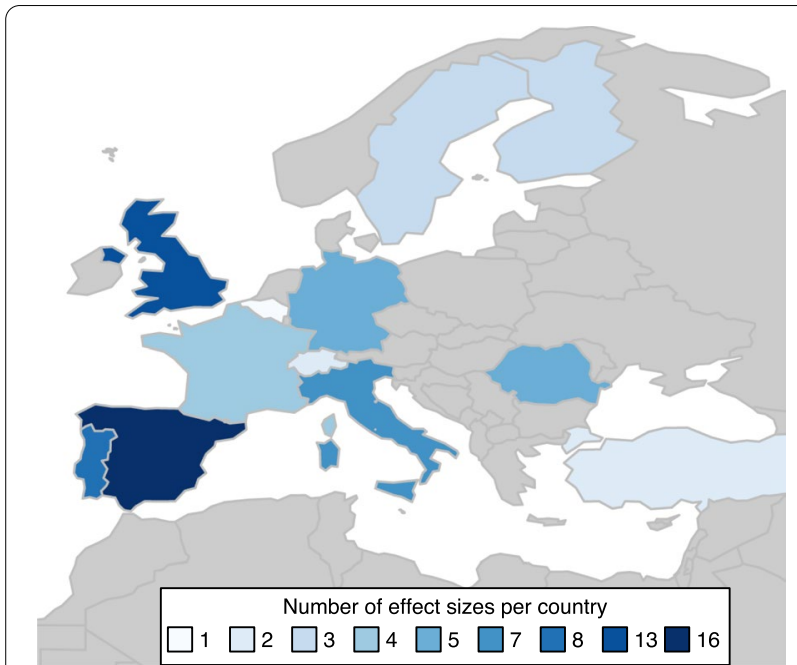

Fig. 2 Map of Europe with the number of effect sizes per country

Studies had been conducted in sites all across Europe and covered data from 1984 to 2019 (Fig. 2). The majority of study sites were located in the Mediterranean with 12 studies from Spain, 8 from Portugal, 5 from Italy and one each from France and Turkey. There were fewer studies from the temperate central European climate. They ranged from the United Kingdom (6), Romania (4), France (2), Germany (2), Switzerland (2) and Belgium (1) to northern Italy (1). The boreal region was represented by four studies from Sweden and two from Finland.

Agroforestry systems were predominately silvopastoral (36 studies, 52 effect sizes), while silvoarable systems were less often a topic of research (13 studies, 17 effect sizes). The impact of agroforestry on biodiversity was evaluated by comparing agroforestry systems to a control type. Most often this control type was a pasture (23 effect sizes), followed by forests (21 effect sizes), abandoned agroforestry systems (13 effect sizes) and cropland (12 effect sizes).

Biodiversity was measured in different taxonomic groups and reported at various levels of detail across studies (Fig. 3). Some studies for example lumped all arthropods, whereas others reported diversity of carabid beetles only. We clustered biodiversity measures into five groups: arthropods, birds, bats, plants and one group with fungi, lichens and bryophytes. Biodiversity effects were mainly measured based on differences in species richness. Five studies with seven effect sizes used other measures, namely family richness [26, 27], log-series [28, 29] or Shannon index [30].

\section{Effects of agroforestry on biodiversity}

The results of the meta-analysis show that there is no general benefit of agroforestry systems to biodiversity (summary effect size $=0.1,95 \% \quad \mathrm{CI}$ $=[-0.03,0.23], z_{d f=68}=1.47, p=0.14, \quad$ Additional file 5). The studies' individual effects sizes show substantial between-study variability (Q =6229, $p<0.0001 ; I^{2}=98.9 \%$; Fig. 4). Some of this heterogeneity was attributed to systematic differences in environmental variables, and 'taxonomic group', 'control type' and 'agroforestry type' could explain $13.5 \%$ of the heterogeneity (marginal $R^{2}$ ).

A subgroup analysis for each agroforestry system, further distinguishing biodiversity effects depending on the control type, revealed that silvoarable systems were significantly more diverse than cropland (Fig. 4 right plot, 'Cropland' summary effect size $=0.46,95 \% \mathrm{CI}$ $\left.=[0.1,0.82], z_{d f=11}=2.52, p=0.012\right)$, with 1.6 times more species in the agroforestry system than in cropland. Comparing the biodiversity of silvoarable systems to forests, they did not differ significantly, but showed a tendency towards higher diversity in forests. In silvopastoral systems, none of the subgroup effect sizes was significant (Fig. 4 left plot). Effect sizes were very heterogeneous and with partly opposing effects, such as forests harbouring a higher bird diversity in relation to agroforestry in one study [31, moderate-evidence study] and the other way around in another study [32, moderate-evidence study].

A subgroup analysis of taxonomic groups showed that birds and arthropods are significantly more diverse across all agroforestry systems (bird summary effect size $=0.23,95 \% \mathrm{CI}=[0.012,0.44], z_{d f=11}=2.07, p=0.038$; arthropods summary effect size $=0.3,95 \% \mathrm{CI}$ $\left.=[0.016,0.59], z_{d f=26}=2.07, p=0.038\right)$. For arthropods a higher resolution was available with subgroups on different taxonomic levels, such as bees or spiders. This increased the number of effect sizes from 27 to 41 as the number of unique combination of taxonomic group and agroforestry system increased. None of the most replicated groups, i.e. beetles, bees and spiders, showed a consistent diversity response to agroforestry (Fig. 5).

\section{Sensitivity analysis and the underlying evidence}

The quality of studies included in this meta-analysis ranged from weak to strong evidence [compare with 33]. Some studies were based on a replicated and controlled design providing the strongest evidence, whereas others used before-after comparison or an observational gradient. We adjusted the study weights according to their level of evidence to assign a lower weight to weaker studies 


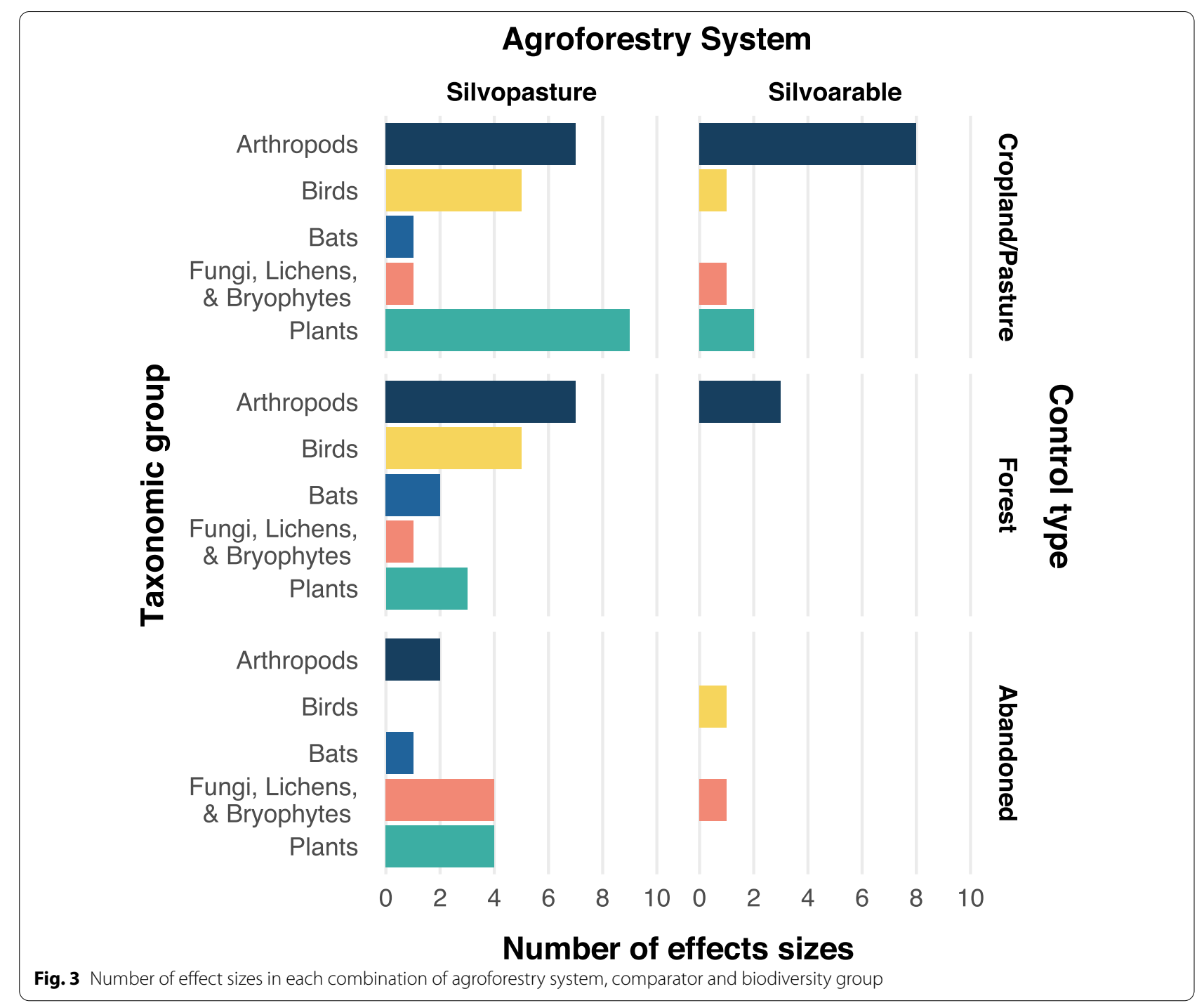

(Additional file 3). The results of the evidence-weighted meta-analysis did not lead to different conclusions and confirmed the results of the traditional inverse-varianceweighted meta-analysis (level-of-evidence-weighted summary effect size $=0.093,95 \% \mathrm{CI}=[-0.003,0.19])$.

Beside the weighting of studies, missing studies due to a publication bias is another obstacle for robust metaanalytical results. According to the funnel plot and Egger's regression test, no publication bias is detectable in our data (Additional files 5 and 6, intercept of Egger's regression $=0.77, t=0.03, p=0.98$ ).

Given that an earlier meta-analysis [23] has found a significant effect of agroforestry on biodiversity, we were interested in the change of the conclusion over time. A cumulative meta-analysis shows that there is a tendency of evidence for a beneficial effect of agroforestry over time. But only at one point in time, in early 2015, when the studies from Garrido-Jurado et al. [34] and Rossetti et al. [35] were added, the confidence interval was above zero (Fig. 6). A meta-analysis conducted in early 2015 would have resulted in an overall significant positive effect of agroforestry on biodiversity. At all other times, between 1991 and today, there is no general evidence for a beneficial effect of agroforestry on biodiversity, and the conclusion remains robust over the time. Another possible bias could have been introduced by systematically investigating a particular taxonomic group during a certain time period, e.g. a peak of bird studies in the 1990s. Taxonomic groups, however, ranged across the whole time period and did not cluster and as such did not bias the results (Fig. 6, colour code). 


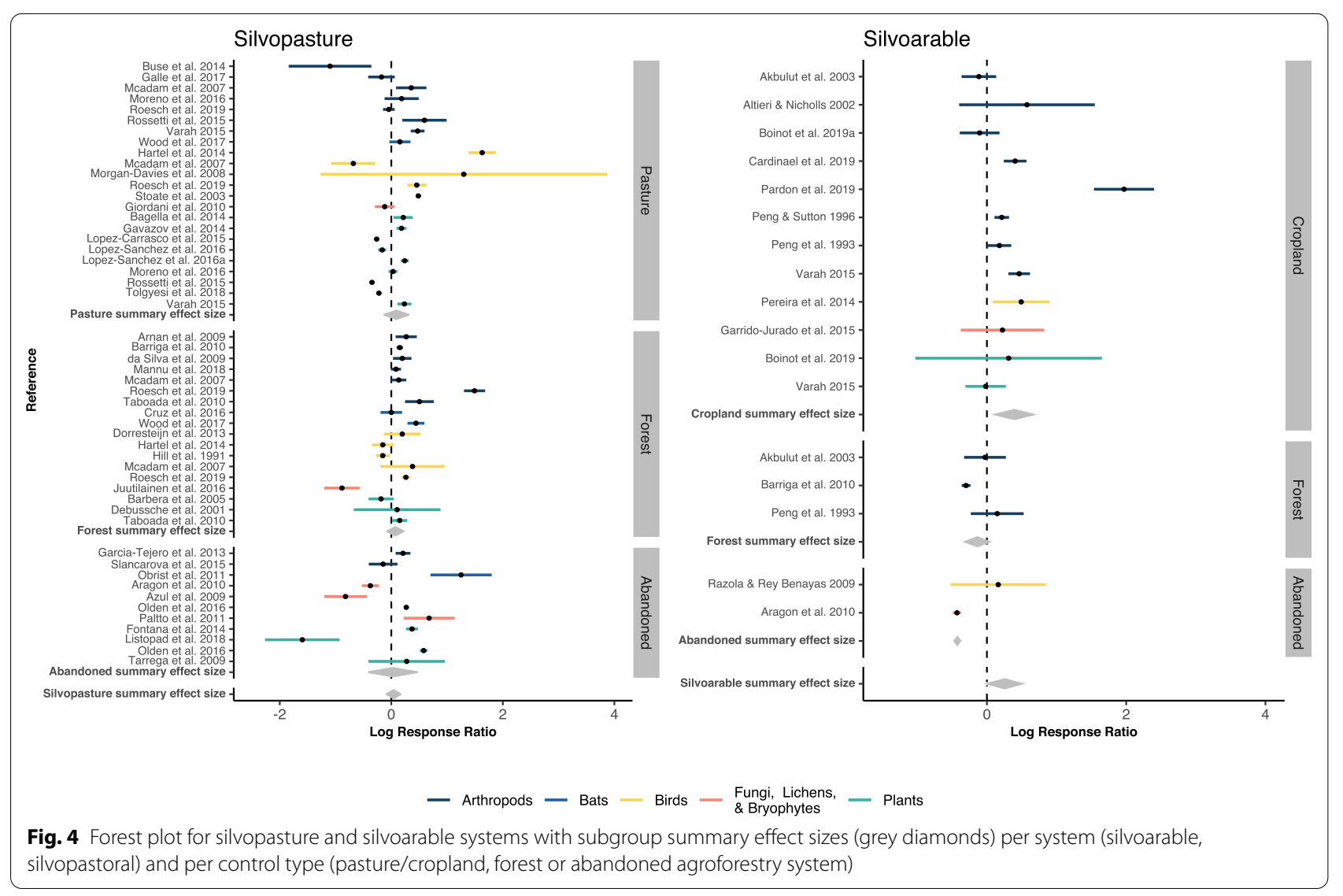

\section{Discussion}

European silvoarable systems host higher biodiversity than cropland, but show a tendency towards lower diversity than forests. In silvopastoral systems there was no evident benefit over either single-use system. Abandoning traditional agroforestry systems and leaving them to shrub encroachment and natural succession did not increase or reduce biodiversity systematically, as was suggested in other studies, and is likely to depend on the number of years since abandonment [36, 37]. Birds and arthropods exhibited significantly higher diversity in agroforestry systems in our subgroup analysis. The higher diversity of arthropods in agroforestry could not be traced back to any particular subgroup such as beetles, spiders or bees. Even within the taxonomic subgroups effects were heterogeneous. Spider diversity, for example, was found to be higher in agroforestry compared to a forest in one study [38, moderate-evidence study], but showed the opposite effect in another study [39, weakevidence study].

Agroforestry covers around 10\% of the agricultural area in the European Union [15]. Among them are traditional and very long established agroforestry sites, such as the
Mediterranean Dehesas and Montado, traditional Spanish and Portugese silvopastures [3]. Land-use history, i.e. the age of the agroforestry system and the previous land-use type, may have a strong impact which is hardly reported or even known to the primary-study authors [20]. As such an older agroforestry system may harbour a different biodiversity than a newly established one; and the same holds for an old-grown forest relative to a more intensively managed younger forest site.

Additional unmeasured drivers operating at the landscape scale may equally determine the biodiversity. The implementation of agroforestry at the field scale does not guarantee the viability of populations of tree-dependent species, but could host these species if additional forest patches are found nearby [40, 41]. Invertebrates for example profit from a diverse landscape beyond the field scale $[42,43]$. Our conclusion are largely based on species richness comparison; communities may well differ in their composition beyond richness [compare e.g. 22, $44,45]$. For conservation decisions, variables such as the occurence of rare and endangered species may be additionally relevant. 


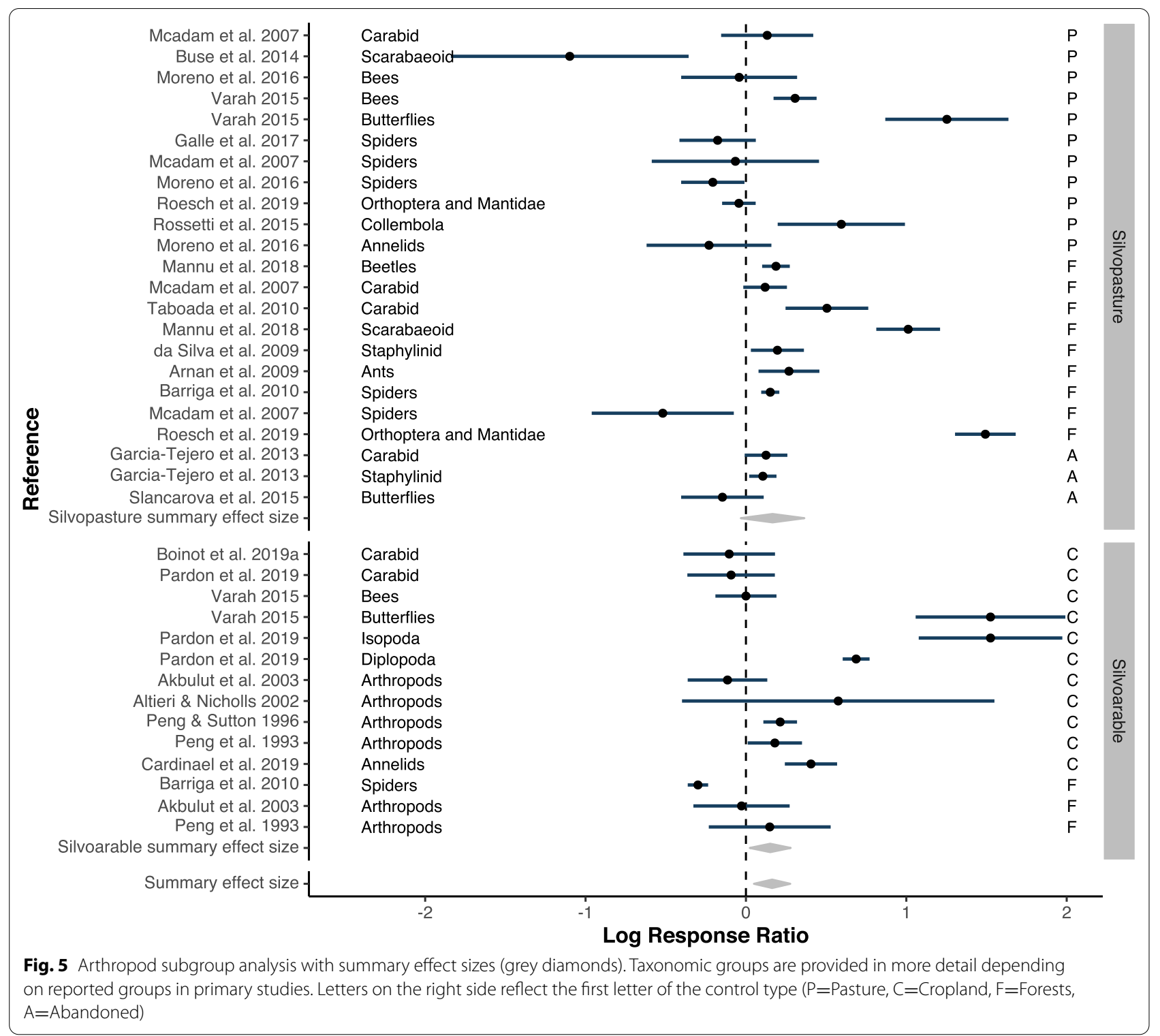

\section{Robustness of meta-analytical results}

Meta-analysis of systematically searched literature provides evidence that is stronger than individual studies, unsystematic literature searches and qualitative synthesis [28, 46, 47]. Conclusions drawn from a meta-analysis nevertheless depend on the robustness of the result, i.e. whether minor changes such as alternating the weighting could reverse the conclusion. Weighting of studies traditionally occurs by inverse variance without considering the differences in study quality and design. In previous work, the underlying evidence and thus the reliability of individual study results was shown to be distinct depending on their study design [48, 49]. Weighting studies proportional to the evidence underlying each individual study is an alternative to the traditional weighting. In our case, results did not change with the alternative weighting approach, but can confirm the robustness of our conclusions.

Meta-analysis has established in ecology and as such updates of already existing meta-analyses can show how and whether conclusions may change over time. In a cumulative meta-analysis, adding new studies according to their publication date, we did not observe a declining effect as observed in other meta-analyses, but the effect remained stable despite very heterogeneous individual study results [50]. In our study we also found that other environmental variables have an influence on the agroforestry-biodiversity relationship. Meta-analysis builds 


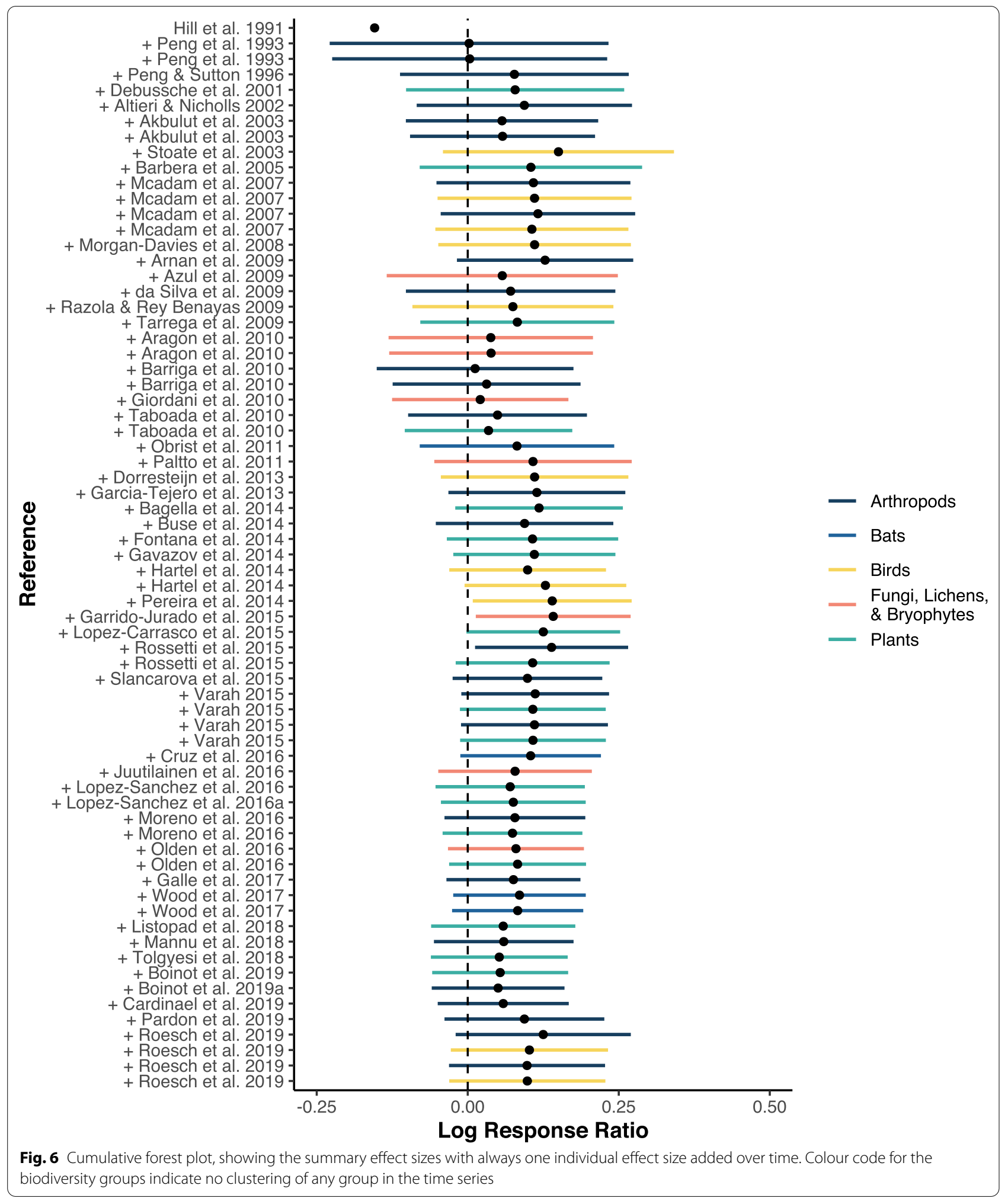

on what is found in the literature, and additional categorical environmental variables used as moderators in meta-analytical models are rarely balanced. The results of our analysis is robust over time and adding new studies is unlikely to impact the results [51], but systematically adding studies on silvoarable systems, which in the current 
meta-analysis make up only one third of silvopastoralstudy contribution, could well influence the results. An increasing number of silvoarable studies may move the overall effect size further towards the positive end and eventually turn the combined result to be significantly positive. Given that silvopastoral systems are dominant in Europe, we are nevertheless convinced that the ratio of silvopastoral and silvoarable studies in our meta-analysis reflects the proportion in which agroforestry systems in Europe occur and provide representative results [15].

Reproducibility of results is a sign of robustness, but challenging and often frail $[52,53]$. The present metaanalysis and the analysis from Torralba et al. [23] have resulted in different conclusions, as we failed to reproduce their results. While Torralba et al. [23] concluded that agroforestry has a positive effect on biodiversity in general, we could confirm a benefit only in relation to cropland. A possible explanation is the different set of studies used in their meta-analysis. Their definition of agroforestry includes studies on hedgerows and woody riparian buffers bordering agricultural field, which we did not consider as agroforestry as they are not actually under silvicultural use. They have also missed study results from biodiversity studies that reported disadvantages of agroforestry [e.g. 54, 55]. Successfully consolidating different results could be achieved by clearly communicating the context in which they apply, providing code and data used in the analysis to posthoc identify differences, and a ranking scale communicating, how confident scientists are with their statements. This is desirable to support decision makers, and has been demonstrated for the policy-relevant IPCC reports [56-58]. In this specific case, where reviews with the same attempt on similar data yield different results, such a confidence statement may indicate that both reviews are indeed very similar in their assessment. In a subgroup analysis of Torralba et al. [23], distinguishing between fungi, arthropods, plants and birds, only birds were significantly positive, which we could confirm in our analysis. In contrast to their results, we have to emphasize that results are heterogeneous. Our review suggests weak effects, and we are only moderately confident about these findings, supposing that the main driver for biodiversity cannot be found in agroforestry but may lie at the landscape scale or be dependent on land-use history.

\section{Conclusion}

Agroforestry increases biodiversity in silvoarable systems compared to cropland and in general for birds and arthropods, but benefits were small and there was no overall positive effect of agroforestry on biodiversity. Outcomes were influenced by the heterogeneity of effect sizes and silvopastoral systems did not show a benefit over either single-use system. While previous reviews were enthusiastic and considered agroforestry to have led to an increase in biodiversity [23], we need to call for caution. In the present evidence assessment, we have identified only few studies providing results based on strong evidence, and those paint a heterogeneous picture, suggesting other variables to interact with positive or negative effects from agroforestry. Systematic reviews and meta-analyses are providing the best available evidence, but they do not automatically guarantee reproducibility. They depend on the quality, quantity and comparability of studies used in the analysis. We suggest to resolve these issues by a detailed reporting, data provision and the communication of heterogeneity. Our study provides results embedded in the context in which agroforestry can lead to a benefit for biodiversity. Together with the knowledge available about the impact of agroforestry on carbon sequestration and other ecosystem services, our results can enrich the discussion on how future subsidies from the Common Agricultural Policy of the European Union can further incorporate agroforestry measures. Future studies on landscape parameters and land-use history are required to disentangle the context in which agroforestry is beneficial for biodiversity.

\section{Methods}

We reviewed the literature on biodiversity in European agroforestry systems and synthesized the results in a meta-analysis. This review is based on the standards of the Collaboration for Environmental Evidence [24, 59-61]. It goes beyond these standards by additionally performing a sensitivity analysis with studies weighted by their evidence to identify the robustness of the results [56].

\section{Literature search}

We used search terms and their synonyms related to 'biodiversity', 'agroforestry' and 'Europe' in the Web of Science to identify the relevant literature (Box 1). Reviews revealed by the Web of Science search were scanned for additional references. In the first screening of articles, we sighted title and abstract and excluded publications that did not fulfil the inclusion criteria (Box 2). In a second screening, we read the full text and applied additional inclusion criteria (Box 2). If an article was included, we extracted the mean diversity, standard deviation and sample size in an agroforestry system and its corresponding reference (control site) along with environmental variables (see Table 1 for the full list of environmental variables). Observational studies were included if a good proxy for a control site was available. This was the case for studies about species groups with limited mobility (e.g. plants or Collembola) looking at distance gradients. 
Table 1 Environmental variables

\begin{tabular}{ll}
\hline Variable name & Categories \\
\hline Agroforestry system & Silvopastoral; silvoarable \\
Control type & Forest, cropland, pasture or abandoned agroforestry systems (generally described as shrub-encroached) \\
Sampling methods & Transects with sweep netting; pitfall traps; pan traps; recording and various other methods \\
Diversity measure & Species richness, family richness or Shannon diversity \\
Sampling year & Numeric ranging from 1984 to 2019 \\
Country of study location & European country \\
Climate zone & Mediterranean (including two summer-moist Atlantic studies), temperate Central European or boreal
\end{tabular}

The values most distant to the agroforestry treatment served as a control in our meta-analysis (see also Additional file 4 column 'comments' for more details). WebPlotDigitizer was used to extract data points from figures [62]. Unique combinations of agroforestry system, control type and taxonomic group were considered from each article.

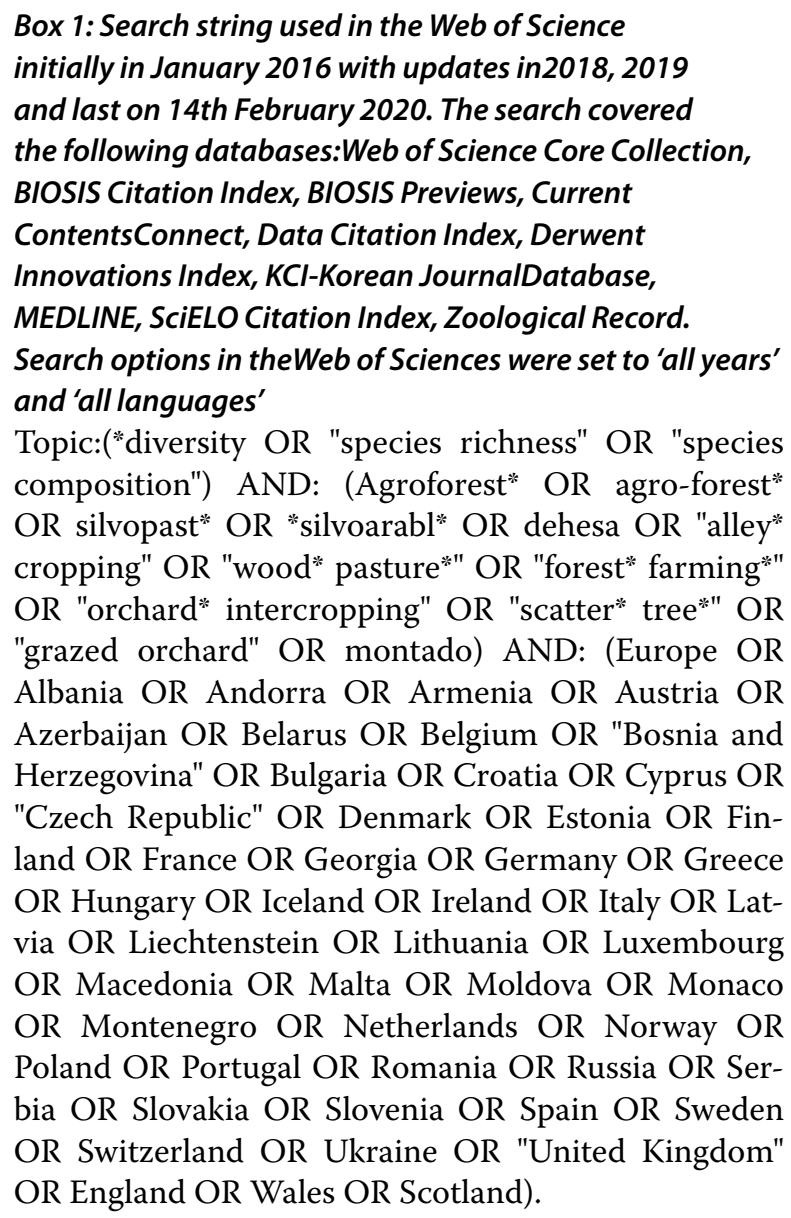

\section{Box 2. Inclusion criteria for studies to be included in this} review

Inclusion criteria for title and abstract screening

-Study sites are located in Europe. Europe ranges from Iceland to the Ural Mountains and from Norway to the Mediterranean Sea and the Black Sea.

-The study is done in an agroforestry system, whereas agroforestry is defined by an area covered by crops or livestock and trees in an alternating way. Buffer strips and hedgerows only bordering an agricultural field or pasture were not considered.

-The study provides information on biodiversity in an agroforestry system.

Additional inclusion criteria for full-text screening

-The study should not discuss conceptual approaches or introduce new methods without quantifying biodiversity in agroforestry.

-If a study reviewed other primary studies, references were verified for inclusion.

-Average species richness or another quantifiable biodiversity measure, such as Shannon diversity, needs to be extractable for an agroforestry system and a corresponding control type in relation to their sample size.

-Full text was searched in the internet open access and through the subscriptions hold by the University of Freiburg. Authors were contacted via e-mail if we could not find or access the full text online. If all these attempts to access the full text of an article failed, the study could not be included.

\section{Analysis}

Meta-analysis is based on effect sizes and here we used log response ratios to compare the biodiversity between 
an agroforestry site and its corresponding control site $[63,64]$. The summary effect of agroforestry on biodiversity was estimated by running a random-effect model, with a random effect for study, and no fixed effect [65]. Heterogeneity was tested with a Q-test for heterogeneity and additionally given by $I^{2}$, the ratio of heterogeneity (i.e. between-study variability) to the total variability (i.e. sum of between- and within-study variability) $[66,67]$. If heterogeneity accounts for large amounts of the total variability, additional environmental variables (moderators), such as sampling method or study location (see Table 1) may improve the model by further explaining parts of the heterogeneity. This was investigated with a mixed-effects model with fixed-effects selection based on a likelihoodratio test of the maximum-likelihood fits [68]. Marginal $R^{2}$ was given to identify the amount of heterogeneity that could be explained by the selected fixed effects $[69,70]$. If the mixed-effects model identified categorical environmental variables influencing the agroforestry-biodiversity relationship, a subsequent subgroup meta-analysis was performed to identify under which circumstances agroforestry has an impact on biodiversity. Analysis was realized in R 4.0.2 using packages 'metafor', 'nlme' and 'MuMIn' [64, 71, 72], see Additional files 4 and 5 for details and R code].

\section{Sensitivity analysis}

Studies are traditionally weighted according to their inverse variance. This method has been criticized for being prone to bias especially with small sample sizes [73]. We tested the robustness of the results by adjusting the weighting by the underlying evidence of each study [compare with 33]. For this purpose, the traditional inverse variance weighting was modified by multiplying the weight with the level of evidence each study provided to reduce the influence of low-evidence studies on the summary effect size. The level of evidence was assessed with help of an evidence assessment tool considering the underlying study design (e.g. case-control or observational) and quality criteria, such as sample size [56]. Publication bias, i.e. the tendency of statistically significant results being more often published than non-significant results, was assessed based on a funnel plot and an Egger's regression test $[64,68,74]$.

\section{Supplementary Information}

The online version contains supplementary material available at https://doi. org/10.1186/s12862-021-01911-9.

Additional file 1. Literature Search Screening. It contains meta information about the abbreviations and the list of literature that was screened: 1439 rows - one row per study - and 14 columns containing information on author, title and journal as well as the inclusion and exclusion criteria.

Additional file 2. Literature included in meta analysis. It contains the full reference of all the 50 studies retained after the literature search
(Additional file 1) and included in the meta analysis. It is also available in the bib format (.bib) for the integration in a reference software.

Additional file 3. Level of evidence assessment. Every column refers to one study. The spreadsheet template is taken from the supplementary material of [28].

Additional file 4. Data for the meta-analysis on biodiversity. The file is a semicolon separated table (.csv) that can be opened in a spreadsheet. It has 29 rows and 21 columns containing information required for the meta-analysis. Meta information about the abbreviations used is found in Additional file 5.

Additional file 5. Description of data tables and R-Code of the analysis. The file is in the R-Markdown format (.rmd) and can be opened via $\mathrm{R}$-Studio or any other text editor. The Appendix 5 is also provided in the $\mathrm{html}$ format including the R-Output of the analysis.

Additional file 6. Funnel Plot. The file is a portal document format (.pdf) with the funnel plot of the analysis.

Additional file 7. Prisma checklist. It is a checklist according to the Preferred Reporting Items for Systematic Reviews and Meta-Analyses (PRISMA) guidelines (http://www.prisma-statement.org/).

\section{Acknowledgements}

We thank authors of primary studies used in this article to contribute to our meta-analysis by sharing their data and providing additional information to their publications. We also want to thank Amelie Göbel who has initiated this project with her master thesis and provided the evidence assessment of some of the primary studies. We are grateful to the initiative'Publication Partners during the Covid-19 lockdown' and our publication partners Dominic Andreas Martin for the wonderful figure design and comments on earlier versions and Jonathan Spencer for text editing.

\section{Authors' contributions}

ACM and CFD designed the study. ACM and MK collected the data. ACM analysed the evidence base. ACM performed the meta-analysis. ACM and CFD wrote the manuscript. All authors read and approved the final manuscript.

\section{Funding}

Open Access funding enabled and organized by Projekt DEAL. This work was initially supported by the 7th framework programme of the European Commission in the project'Operational Potential of Ecosystem Research Applications'(OPERAs, grant number 308393, www.operas-project.eu) providing funding for the PhD thesis of the first author from 2013 to 2016. The STAY! scholarship of the Neue Universitätsstiftung Freiburg funded the first author from 2019 to 2020. The article processing charge was funded by the Baden-Württemberg Ministry of Science, Research and Art and the University of Freiburg in the funding programme Open Access Publishing.

\section{Availability of data and materials}

All data required for the replication of the analysis are available in the supplementary material.

\section{Declarations}

Ethics approval and consent to participate

Not applicable.

\section{Consent for publication}

Not applicable.

\section{Competing interests}

The authors declare that they have no competing interests.

\section{Author details}

${ }^{1}$ Nature Conservation and Landscape Ecology, University of Freiburg, Tennenbacherstr. 4, 79106 Freiburg, Germany. ${ }^{2}$ Biometry and Environmental System Analysis, University of Freiburg, Tennenbacherstr. 4, 79106 Freiburg, Germany. 
Received: 23 March 2021 Accepted: 9 September 2021

Published online: 23 October 2021

\section{References}

1. Lundgren B. Introduction. Agrofor Syst. 1982;1(1):3-6. https://doi.org/10. 1007/BF00044324.

2. FAO: Agroforestry and Tenure, vol 8. Forestry Working Paper, Rome; 2019. p. 40. http://www.fao.org/3/ca4662en/CA4662EN.pdf

3. Nerlich K, Graeff-Hönninger S, Claupein W. Agroforestry in Europe: a review of the disappearance of traditional systems and development of modern agroforestry practices, with emphasis on experiences in Germany. Agrofo Syst. 2013;87(5):1211. https://doi.org/10.1007/ s10457-013-9618-9.

4. Mosquera-Losada MR, McAdam JH, Romero-Franco R, Santiago-Freijanes $J$ J, Rigueiro-Rodriguez A. Definitions and Componentns of Agroforestry Practices in Europe. In: Rigueiro-Rodriguez A, McAdam J, MosqueraLosada MR, eds. Agroforestry in Europe: current status and future prospects, Chap 1. Springer: Dordrecht; 2009. p. 3.

5. Benton TG, Vickery JA, Wilson JD. Farmland biodiversity: Is habitat heterogeneity the key? Trends in Ecology and Evolution 2003;18(4):182-188. https://doi.org/10.1016/S0169-5347(03)00011-9. arXiv:1011.1669v3

6. Beckmann M, Gerstner K, Akin-Fajiye M, Ceauşu S, Kambach S, Kinlock NL, Phillips HRP, Verhagen W, Gurevitch J, Klotz S, Newbold T, Verburg PH, Winter M, Seppelt R. Conventional land-use intensification reduces species richness and increases production: a global meta-analysis. Global Change Biol. 2019;25:1941-56. https://doi.org/10.1111/gcb.14606.

7. Homburg K, Drees C, Boutaud E, Nolte D, Schuett W, Zumstein P, Ruschkowski E, Assmann T. Where have all the beetles gone? Long-term study reveals carabid species decline in a nature reserve in Northern Germany. Insect Conserv Divers. 2019;12:268-77. https://doi.org/10.1111/ icad.12348.

8. IPBES: summary for policymakers of the global assessment report on biodiversity and ecosystem services of the Intergovernmental SciencePolicy Platform on Biodiversity and Ecosystem Services. Technical Report May 2019, Intergovernmental Science- Policy Platform on Biodiversity and Ecosystem Services; 2019.

9. Báldi A. Habitat heterogeneity overrides the species-area relationship. J Biogeogr. 2008;35(4):675-81. https://doi.org/10.1111/j.1365-2699.2007. 01825.x.

10. Maskell LC, Botham M, Henrys P, Jarvis S, Maxwell D, Robinson DA, Rowland CS, Siriwardena G, Smart S, Skates J, Tebbs EJ, Tordoff GM, Emmett BA. Exploring relationships between land use intensity, habitat heterogeneity and biodiversity to identify and monitor areas of High Nature Value farming. Biol Conserv. 2019;231:30-8. https://doi.org/10.1016/j.biocon. 2018.12.033.

11. Bhagwat SA, Willis KJ, Birks HJB, Whittaker RJ. Agroforestry: a refuge for tropical biodiversity? Trend Ecol Evol. 2008;23(5):261-7. https://doi.org/ 10.1016/j.tree.2008.01.005

12. Fagerholm N, Torralba M, Burgess PJ, Plieninger T. A systematic map of ecosystem services assessments around European agroforestry. Ecol Indicators. 2016:62:47-65. https://doi.org/10.1016/j.ecolind.2015.11.016.

13. McAdam JH, Burgess PJ, Graves AR, Rigueiro-Rodriguez A, MosqueraLosada MR. Classifications and functions of agroforestry systems in Europe. In: Rigueiro-Rodríguez, A, McAdam J, Mosquera-Losada MR, eds. Agroforestry in Europe: Current Status and Future Prospects, Chap 2. Springer: Dordrecht; 2009. p. 21.

14. Palma J, Graves AR, Burgess PJ, van der WerfW, Herzog F. Integrating environmental and economic performance to assess modern silvoarable agroforestry in Europe. Ecol Econ. 2007;63(4):759-67. https://doi.org/10. 1016/j.ecolecon.2007.01.011.

15. den Herder M, Moreno G, Mosquera-Losada RM, Palma JHN, Sidiropoulou A, Santiago Freijanes JJ, Crous-Duran J, Paulo JA, Tomé M, Pantera A Papanastasis VP, Mantzanas K, Pachana P, Papadopoulos A, Plieninger T, Burgess PJ. Current extent and stratification of agroforestry in the European Union. Agric Ecosyst Environ. 2017;241:121-32. https://doi.org/10. 1016/j.agee.2017.03.005

16. Mosquera-Losada MR, Santiago-Freijanes JJ, Rois-Díaz M, Moreno G, Herder MD. Agroforestry in Europe: a land management policy tool to combat climate change. Land Use Policy. 2018;78:603-13. https://doi.org/ 10.1016/j.landusepol.2018.06.052.

17. Santiago-Freijanes JJ, Pisanelli A, Rois-Díaz M, Aldrey-Vázquez JA, Rigueiro-Rodríguez A, Pantera A, Vityi A, Lojka B, Ferreiro-Domínguez N, Mosquera-Losada MR. Agroforestry development in Europe: policy issues. Land use policy. 2018;76:144-56. https://doi.org/10.1016/j.landusepol. 2018.03.014.

18. De Beenhouwer M, Aerts R, Honnay O. A global meta-analysis of the biodiversity and ecosystem service benefits of coffee and cacao agroforestry. Agric Ecosyst Environ. 2013;175:1-7. https://doi.org/10.1016/j.agee.2013. 05.003 .

19. Santos PZF, Crouzeilles R, Sansevero JBB. Can agroforestry systems enhance biodiversity and ecosystem service provision in agricultural landscapes? A meta-analysis for the Brazilian Atlantic Forest. For Ecol Manag. 2019;433:140-5. https://doi.org/10.1016/j.foreco.2018.10.064.

20. Martin DA, Osen K, Grass I, Hölscher D, Tscharntke T, Wurz A, Kreft H. Land-use history determines ecosystem services and conservation value in tropical agroforestry. Conserv Lett. 2020. https://doi.org/10.1111/conl. 12740 .

21. Bohada-Murillo M, Castano-Villa GJ, Fontúrbel FE. The effects of forestry and agroforestry plantations on bird diversity: a global synthesis. Land Degrad Dev. 2019. https://doi.org/10.1002/ldr.3478.

22. Boinot S, Poulmarc'h J, Méziére D, Lauri PÉ, Sarthou JP. Distribution of overwintering invertebrates in temperate agroforestry systems: implications for biodiversity conservation and biological control of crop pests. Agric Ecosyst Environ. 2019. https://doi.org/10.1016/j.agee.2019.106630.

23. Torralba M, Fagerholm N, Burgess PJ, Moreno G, Plieninger T. Do European agroforestry systems enhance biodiversity and ecosystem services? A meta-analysis. Agric Ecosyst Environ. 2016;230:150-61. https://doi.org/ 10.1016/j.agee.2016.06.002

24. Collaboration for Environmental Evidence: Guidelines and Standards for Evidence synthesis in Environmental Management. Technical report Bangor, UK, Version 5.0; 2018. http://www.environmentalevidence.org/ information-for-authors

25. Moher D, Liberati A, Tetzlaff J, Altman DG. Preferred reporting items for systematic reviews and meta-analyses: the PRISMA statement. PLoS Med. 2009;6(7):1000097. https://doi.org/10.1371/journal.pmed.1000097.

26. Akbulut S, Keten A, Stamps WT. Effect of alley cropping on crops and arthropod diversity in Duzce, Turkey. J Agron Crop Sci. 2003;189(4):261-9. https://doi.org/10.1046/j.1439-037X.2003.00042.x.

27. Mannu R, Pilia O, Leonarda M, Marcello F. Variability of beetle assemblages in Mediterranean cork oak woodlands : does the higher taxa approach reliably characterize a specific response to grazing? Biodivers Conserv. 2018;27(14):3599-619. https://doi.org/10.1007/s10531-018-1616-9.

28. Peng RK, Incoll LD, Sutton SL, Wright C, Chadwick A. Diversity of airborne arthropods in a silvoarable agroforestry system. J Appl Ecol. 1993;30:551-62.

29. Peng RK, Sutton SL. The activity and diversity of ground arthropods in an agroforestry system. Proceedings of the 49th New Zealand Plant Protection Conference, 1996; 309-313.

30. Stoate C, Araújo M, Borralho R. Conservation of European farmland birds: abundance and species diversity. Ornis Hungarica 2003;12-13 (Tucker 1999), 33-40.

31. Hill DA, Lambton S, Proctor I, Bullock I, Hill DA. Winter bird communities in woodland in the forest of Dean, England, and some implications of livestock grazing. Bird Study. 1991;38(1):57-70. https://doi.org/10.1080/ 00063659109477068.

32. Rösch V, Hoffmann M, Diehl U, Entling MH. The value of newly created wood pastures for bird and grasshopper conservation. Biol Conserv. 2019 https://doi.org/10.1016/j.biocon.2019.07.036.

33. Mupepele A-C, Dormann CF. Influence of forest harvest on nitrate concentration in temperate streams - a meta-analysis. Forests. 2017;8(5):114. https://doi.org/10.3390/f8010005.

34. Garrido-Jurado I, Fernández-bravo M, Campos C, Quesada-moraga E. Diversity of entomopathogenic Hypocreales in soil and phylloplanes of five Mediterranean cropping systems. J Invert Pathol. 2015;130:97-106. https://doi.org/10.1016/j.jip.2015.06.001

35. Rossetti I, Bagella S, Cappai C, Caria MC, Lai R, Roggero PP, da Silva MP, Sousa JP, Querner P, Seddaiu G. Isolated cork oak trees affect soil properties and biodiversity in a Mediterranean wooded grassland. Agric Ecosyst Environ. 2015;202:203-16. https://doi.org/10.1016/j.agee.2015.01.008. 
36. Obrist MK, Rathey E, Bontadina F, Martinoli A, Conedera M, Christe P, Moretti M. Response of bat species to sylvo-pastoral abandonment. For Ecol Manag. 2011;261(3):789-98. https://doi.org/10.1016/j.foreco.2010.12. 010.

37. Plieninger $T$, Hui $C$, Gaertner $M$, Huntsinger $L$. The impact of land abandonment on species richness and abundance in the Mediterranean Basin: a meta-analysis. PLoS ONE. 2014. https://doi.org/10.1371/journal. pone.0098355.

38. Barriga JC, Lassaletta L, Moreno AG. Ground-living spider assemblages from Mediterranean habitats under different management conditions. J Arachnol. 2010;38(2):258-69. https://doi.org/10.1636/P09-40.1.

39. Mcadam JH, Sibbald AR, Teklehaimanot Z, Eason WR. Developing silvopastoral systems and their effects on diversity of fauna. Agrofor Syst. 2007;70(1):81-9. https://doi.org/10.1007/s10457-007-9047-8.

40. Haggar J, Pons D, Saenz L, Vides M. Contribution of agroforestry systems to sustaining biodiversity in fragmented forest landscapes. Agric Ecosyst Environ. 2019. https://doi.org/10.1016/j.agee.2019.06.006.

41. Batáry P, Gallé R, Riesch F, Fischer C, Dormann CF, Mußhoff O, Császár P, Fusaro S, Gayer C, Happe AK, Kurucz K, Molnár D, Rösch V, Wietzke A, Tscharntke T. The former Iron Curtain still drives biodiversity-profit tradeoffs in German agriculture. Nat Ecol Evol. 2017;1 (9):1279-84. https://doi. org/10.1038/s41559-017-0272-X.

42. Gonthier DJ, Ennis KK, Farinas S, Hsieh H-Y, Tscharntke T, Iverson AL, Cardinale BJ, Perfecto I. Biodiversity conservation in agriculture requires a multi-scale approach. Proc R Society B. 2014;281:20141358.

43. Hass AL, Kormann UG, Tscharntke T, Clough Y, Fahrig L, Martin J-L, Baillod $A B$, Baudry J, Bertrand C, Bosch J, Brotons L, Burel F, Georges R, Giralt D, Marcos-Garcia MA, Ricarte A, Siriwardena G, Batary P. Landscape configurational heterogeneity by small-scale agriculture, not crop diversity, maintains pollinators and plant reproduction in western Europe. Proc $R$ Society B. 2018:285:20172242. https://doi.org/10.1098/rspb.2017.2242.

44. Jowett K, Milne AE, Metcalfe H, Hassall KL, Potts SG, Senapathi D, Storkey J. Species matter when considering landscape effects on carabid distributions. Agric Ecosyst Environ. 2019. https://doi.org/10.1016/j.agee.2019. 106631.

45. Slancarova J, Garcia-Pereira P, Fric ZF, Romo H, Garcia-Barros E. Butterflies in Portuguese 'montados': relationships between climate, land use and life-history traits. J Insect Conserv. 2015;19(5):823-36. https://doi.org/10. 1007/s10841-015-9801-6.

46. Dicks LV, Walsh JC, Sutherland WJ. Organising evidence for environmental management decisions: a'4S' hierarchy. Trends Ecol Evol. 2014;29(11):1-7. https://doi.org/10.1016/j.tree.2014.09.004.

47. Pullin AS, Knight TM. Support for decision making in conservation practice: an evidence-based approach. J Nat Conserv. 2003;1 1(2):83-90.

48. Mupepele A-C, Dormann CF. Environmental management: synthesize evidence to steer decisions. Nature. 2016;529(7587):466-466. https://doi. org/10.1038/529466b

49. Christie AP, Amano T, Martin PA, Shackelford GE, Simmons BI, Sutherland WJ. Simple study designs in ecology produce inaccurate estimates of biodiversity responses. J Appl Ecol. 2019;56(12):2742-54. https://doi.org/ 10.1111/1365-2664.13499.

50. Koricheva J, Kulinskaya E. Temporal instability of evidence base: a threat to policy making? Trends Ecol Evol. 2019;34(10):895-902. https://doi.org/ 10.1016/j.tree.2019.05.006

51. Grainger MJ, Bolam FC, Stewart GB, Nilsen EB. Evidence synthesis for tackling research waste. Nat Ecol Evol. 2020. https://doi.org/10.1038/ s41559-020-1141-6.

52. Baker M. Is there a reproducibility crisis? Nature. 2016;533:452-4. https:// doi.org/10.1038/533452a.

53. Editorial: checklists work to improve science. Nature 2018:556(7701):273274. https://doi.org/10.1038/d41586-018-04590-7.

54. Azul AM, Castro P, Sousa JP, Freitas H. Diversity and fruiting patterns of ectomycorrhizal and saprobic fungi as indicators of land-use severity in managed woodlands dominated by Quercus suber- a case study from southern Portugal Anabela. Can J For Res. 2009;39:2404-17. https://doi. org/10.1139/X09-148.
55. García-Tejero S, Taboada Á, Tárrega R, Salgado JM. Land use changes and ground dwelling beetle conservation in extensive grazing dehesa systems of north-west Spain. Biol Conserv. 2013;161:58-66. https://doi. org/10.1016/j.biocon.2013.02.017.

56. Mupepele A-C, Walsh JC, Sutherland WJ, Dormann CF. An evidence assessment tool for ecosystem services and conservation studies. Ecol Appl. 2016;26(5):1295-301. https://doi.org/10.1890/15-0595.

57. Moss RH. The IPCC: policy relevant (not driven) scientific assessment. A comment on Sonja Boehmer-Christiansen's: Global climate protection policy: the limits of scientific advice.' Global Environ Change. 1995;5(3):171-4. https://doi.org/10.1016/0959-3780(95)00058-V.

58. Larigauderie A, Mooney HA. The Intergovernmental science-policy Platform on Biodiversity and Ecosystem Services: moving a step closer to an IPCC-like mechanism for biodiversity. Curr Opin Environ Sustain. 2010;2(1-2):9-14. https://doi.org/10.1016/j.cosust.2010.02.006.

59. Pullin AS, Stewart GB. Guidelines for systematic review in conservation and environmental management. Conserv Biol. 2006;20(6):1647-56.

60. Pullin A, Frampton G, Jongman R, Kohl C, Livoreil B, Lux A, Pataki G, Petrokofsky G, Podhora A, Saarikoski H, Santamaria L, Schindler S, SousaPinto I, Vandewalle M, Wittmer H. Selecting appropriate methods of knowledge synthesis to inform biodiversity policy. Biodivers Conserv. 2016;25(7):1285-300. https://doi.org/10.1007/s10531-016-1131-9.

61. Dicks LV, Wright HL, Ashpole JE, Hutchison J, McCormack CG, Livoreil $B$, Zulka KP, Sutherland WJ. What works in conservation? Using expert assessment of summarised evidence to identify practices that enhance natural pest control in agriculture. Biodivers Conserv. 2016;25(7):1383-99. https://doi.org/10.1007/s10531-016-1133-7.

62. Rohatgi A. WebPlotDigitizer-extract data from plots, images, and maps. Version 4.0; 2017

63. Viechtbauer W. Conducting meta-analyses in R with the metafor Package. J Stat Softw. 2010;36(3):1-48.

64. Koricheva J, Gurevitch J, Mengersen K. Handbook of Meta-analysis in Ecology and Evolution. Princeton University Press: Princeton and Oxford; 2013. p. 498. http://books.google.com/books?id=130XBPrOkuYC\&pgis=1.

65. Gurevitch J, Nakagawa S. Research synthesis methods in ecology. In: Ecological Statistics: Contemporary Theory and Application, Chap 9. Princeton University Press: Princeton and Oxford; 2015

66. Cochran WG. The combination of estimates from different experiments. Biometrics. 1954;10:1001-129.

67. Higgins JPT, Thompson SG. Quantifying heterogeneity in a meta-analysis. Stat Med. 2002;21(11):1539-58. https://doi.org/10.1002/sim.1186.

68. Nakagawa S, Santos ESA. Methodological issues and advances in biological meta-analysis. Evol Ecol. 2012;26(5):1253-74. https://doi.org/10.1007/ s10682-012-9555-5.

69. Nakagawa S, Schielzeth H. A general and simple method for obtaining R2 from generalized linear mixed-effects models. Methods Ecol Evol. 2013;4(2):133-42. https://doi.org/10.1111/j.2041-210x.2012.00261.x.

70. Martin PA, Newton AC, Pfeifer M, Khoo MS, Bullock JM. Impacts of tropical selective logging on carbon storage and tree species richness: a metaanalysis. For Ecol Manag. 2015;356:224-33. https://doi.org/10.1016/j. foreco.2015.07.010.

71. Bartoń K. MuMIn: Multi-Model Inference. Technical report, R package version 1.43.15; 2019.

72. Pinheiro JC, Bates DM, DebRoy S, Sarkar D. nlme: linear and nonlinear mixed effects models; 2020. https://cran.r-project.org/package=nlme.

73. Doncaster CP, Spake R. Correction for bias in meta-analysis of littlereplicated studies. Methods Ecol Evol. 2018;9(3):634-44. https://doi.org/ 10.1111/2041-210X.12927.

74. Egger M, Davey Smith G, Schneider M, Minder C. Bias in meta-analysis detected by a simple, graphical test. BMJ Clin Res. 1997;315(7109):62934. https://doi.org/10.1136/bmj.316.7129.469.

\section{Publisher's Note}

Springer Nature remains neutral with regard to jurisdictional claims in published maps and institutional affiliations. 